\title{
Investigating the Success and the Advantages of Using ERP System in KSA Context
}

\author{
Mohammad Samir Abdel-Haq \\ Dar Al Uloom University, Saudi Arabia \\ mohdsamir@dau.edu.sa
}

\author{
Houcine Chatti \\ Dar Al Uloom University, Saudi Arabia \\ houcine@dau.edu.sa
}

\author{
Evan Asfoura \\ Dar Al Uloom University, Saudi Arabia \\ evan@dau.edu.sa
}

\begin{abstract}
Enterprise resource planning (ERP) is an important innovation, affecting the business world by generating improvements both tangible and intangible in large companies and small and medium enterprises (SME). This study focuses on the determinants of success and the advantages of the adoption of this technology. To address these points, a comprehensive literature survey was carried out in order to formulate an original research model for ERP success evaluation and provide a prospect for IT infrastructure and integration. The model, thus suggested and taken within the Kingdom of Saudi Arabia (KSA) context, examines in a systematic approach the relation between the ERP acceptance determinants, the effects of the process of ERP systems diffusion, and the impacts expected on organizational performance. Obtained results underline two key determinants of ERP projects success: First, the preponderance of information control and the improvement in the use of competences. The second factor is the quality of team projects, the definition of team's mission, training, business processes reengineering, user acceptance, top management support and the selection of the ERP solution.
\end{abstract}

Keywords-ERP; IT infrastructure; key success factors; ERP benefit; systematic approach

\section{INTRODUCTION}

Businesses are becoming more and more inclined to adopt integrated management systems. The growing interest in enterprise resource planning (ERP) solutions is due to the promise of such systems for both large companies and small and medium enterprises (SMEs). In the past, this innovation was only possible for very large multinational companies. In 1998, almost $40 \%$ of firms with more than $\$ 1$ trillion in annual revenue implement ERP systems [1]. Today, this vision is different, the brightest future growth of sales of these systems is at the level of medium-sized companies [2]. Most companies that have acquired an ERP solution have done so primarily because of their capacity to better respond to the need for change in their business environment [3]. This solution, aimed to integrate application software to be used as a management process transformation machine. It is a fact that the transition to a large-scale ERP solution is no longer limited to the acquisition of hardware and software, but the main challenge in implementing an ERP solution is change management $[4,5]$ and knowledge management [36]. In other words, the challenges of implementing an ERP are not only technical, they also involve human and organizational aspects.
About half of the ERP transition projects failed to achieve projected benefits as managers underestimated efforts to invest in change management [6]. Well-known companies [7] have failed to implement an ERP system. As a result, companies are facing a paradoxical situation: on the one hand, the high potential of gain resulting from the installation of an ERP system and, on the other hand, the risks of failure. The broad scope of an ERP and the changes in workflows that accompany its implementation increase both risks and expected benefits [8]. In this perspective, which is situated within the paradigm of the contribution of information systems to organizational performance, the objective of this research is to assess the postimplementation evaluation of the adoption success of the ERP. The issue is, therefore, part of the theme of the impact of IT on organizational performance. This research also tries to evaluate the organizational benefits following the implementation of ERP systems and to determine the key success factors of its adoption.

\section{THEORITICAL FRAMEWORK}

The modeling process of the evaluation is carried out in two stages. First, the determinants of success of ERP implementation and information systems are clarified, in general. Then, the potential benefits of ERP implementation in terms of organizational performance are identified. The modeling effort focuses on explaining the effects of spreading ERP innovation in terms of organizational performance, through its adoption process.

\section{A. Determinants of Success of ERP Adoption}

Four distinct categories of success factors for adoption have been identified in $[9,10]$ : The first category relates to the determinants of success of information systems with factors such as the role of users $[11,12]$, the availability of appropriate resources and skills, and the presence of a sponsor [13]. The second category relates to the determinants of success that can be extended to software packages. Factors such as the general management commitment, and factors related to the implementation process, such as the rigorous management of the project, hardware and software issues, the software selection, or the absence of training support $[9,35]$. The third category concerns the specific determinants of the management of the ERP implementation project. Factors such as communication, recruitment of necessary staff, customer consultation, implementation of a project plan/schedule, 
supervision and feedback at each step and troubleshooting [14], are all important to successfully manage the ERP project. The last category of success factors relates to the actual implementation of ERP systems. In addition to standard project management factors, information technology projects also require additional success factors because of their impact on an organization's structure and business processes.

It should be emphasized that the success of an ERP implementation, defined in terms of determining factors, is limited, if its relationship with the organizational and cultural context is ignored [15]. The list of success factors presents a static perspective of success and does not identify the processes by which these factors operate as well as their links or correlations [9]. As a result, factors can be usefully combined with approaches that focus on the broader understanding of contextual and "process" characteristics, to better explain how and why factors and outcomes are related $[9,15]$. Authors in [16] examined the determinants of successful ERP implementation in Saudi Arabia, and they proposed a conceptual model which was developed based on internal and external factors. The internal factors covered business process reengineering, team competence, project management support, and top management support. The external factors covered vendor support and consultant competency. Authors in [17] defined critical success factors (CSFs) contributing to the success of ERP implementation in Saudi Arabia. The research identified 13 most important ERP CSFs, extracted from previous studies in this field.

\section{B. Evaluation Factors of ERP Impact}

Several studies and numerous examples of companies deal with the success of the ERP implementation, process and analyze the post-implementation benefits notably through their impact on business performance [18-22]. Authors in [18] summarize the impact of ERP. Table I explains the taxonomy of benefits across five dimensions. This structure is validated and consolidated in [23]. It constitutes an indispensable contribution, both theoretical and practical, to differentiate the impacts of ERP, to be usefully retained in the construction of the theoretical scheme of this research.

\section{Theoretical Scheme of Research}

Based on the theoretical foundations, a theoretical scheme for evaluating the post-implementation success of ERP was developed. This schema is a systemic representation of the evaluation at a given moment of the process of transformation of resources used during implementation. It postulates the existence of a theoretical structure of the concepts mobilized, to study causal relationships between the identified determinants of success and the characteristics of innovation (in terms of advantage technical and enhancement of IT infrastructure capabilities) and IT application integration, with the success of ERP adoption and implementation. This schema is a simplified representation of reality that aims to establish direct and indirect effects of the two explanatory levels (mobilized resources and transformation process) on the level of the benefits derived from the use of an ERP. Based on this systemic approach, widely used in management science to evaluate IT performance and impact [24], the theoretical scheme, shown in Figure 1, presents a three-dimensional structure for the levels of analysis.

\begin{tabular}{|c|c|}
\hline \multicolumn{2}{|c}{ TABLE I. } \\
\hline Dimensions & Sub BENEFITS [18] \\
\hline Operational & Cost reduction \\
& Deadline mitigation \\
Improved productivity \\
Quality improvement \\
Improved customer service
\end{tabular}

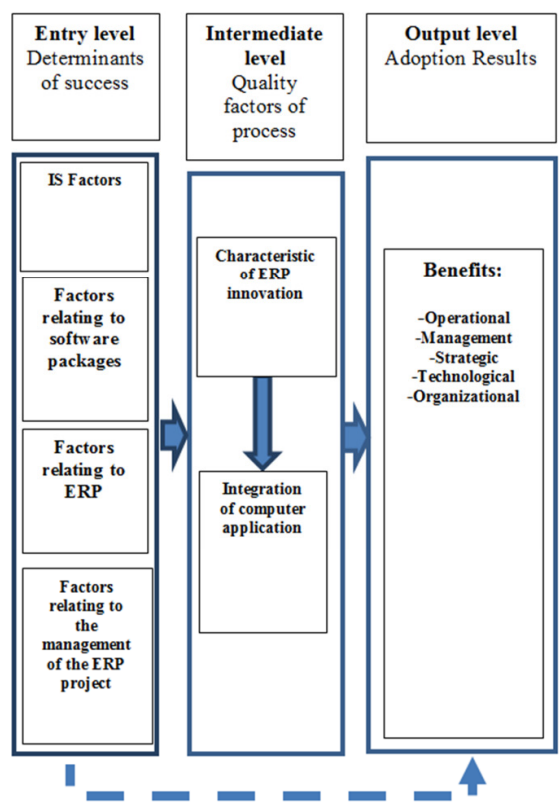

Fig. 1. Theoretical scheme of determinants of adoption success

Regarding Figure 1, one can see an entry level, characterizing the resources or critical success factors (CSF) that were mobilized during the pre-implementation phase of an ERP (relating to information systems, software packages, project management). These resources are likely to affect both the implementation of ERP and its expected organizational performance. This level of theoretical analysis therefore 
considers the facilitating factors of a complex process (black box) of IT acceptance, which aims to efficiently transform the resources mobilized into management results. An intermediate level includes the factors that describe ERP implementation, that is, the factors that formalize the complex process of adoption and IT integration, as the new organizational IS. These are factors that express the effects of the decision to innovate and integrate, through perceptions (in terms of success or failure) of the planning and implementation of the technology [25]. The model uses them, for each of the two mentioned sub-processes (innovation and integration), as "factors of process quality" (FQP) of adoption. An output level describes the success of ERP adoption. These factors reflect the impacts of ERP (of its adoption and its integration), in terms of the benefits of ERP implementation.

\section{Conceptual Model and Research Premise}

Beyond this first exploratory approach and the effort of theoretical structuring, this work aims at proposing an original conceptual model intended to validate the premises of existing relations between the concepts characterizing the three levels of the scheme: the resources mobilized during ERP implementation, IT infrastructure opportunities, integration and organizational performance. The inclusion of quality factors of process describing the IT infrastructure and the integration of applications is a rather new and interesting perspective in understanding the ERP adoption process and in understanding its conditions of success. A study of 20 Canadian companies focused on the challenges of updating IT infrastructure during ERP implementation showed that almost $50 \%$ of these companies have deployed a new infrastructure to support the requirements of the software package, and they migrated from a "mainframe" architecture to a client/server architecture [26]. This update of the IT infrastructure typically leads companies to replace their old critical systems with fully integrated systems [19]. In addition, several studies supported the thesis that system integration is directly related to the performance. The greater the difference between the degree of integration before and after ERP implantation, the greater the benefits obtained [27]. The conceptual model (Figure 2) presents two kinds of causal relationships between the variables of the three conceptual levels: direct and/or indirect dependency relationships. This paper is limited to studying the existence of three direct causal relationships, which are the subject of premises, between levels 1 and $2(\mathrm{P} 1), 2$ and $3(\mathrm{P} 2)$, and in level 2 (P3):

- P1: The key success factors of an ERP implementation directly and positively influence the improvement of the possibilities of the IT infrastructure.

- P2: Improving the possibilities of the IT infrastructure directly and positively influences the integration of applications.

- P3: Application integration directly and positively influences ERP implementation benefits.

\section{E. Methodological Framework of Research}

This is an exploratory study [28], the methodological approach is part of the grounded theory method (GTM) approach [29], and advocated as a response to the "rigid positivism" in [30]. Due to the specificity of the situation and the research object, it is difficult to fully rely on the results of the work that has been done on IT adoption. ERP systems are considered both as a major technological innovation and a complex machine of re-engineering having a very important impact on the development and transformation of the company. Using directly quantitative methods, without the use of exploratory analysis, to test models that are developed solely from the literature cannot favor the reliability and the actualization of the results generated by this research. IT is characterized by a short life cycle where yesterday's technology is becoming obsolete today. In this research work, the qualitative data collection technique was chosen. Focused, non-directive and semi-structured personal interviews were conducted. The choice of this type of interviews seems to achieve the best fit between the degrees of freedom left to the respondent, and the degree of depth of the information sought.

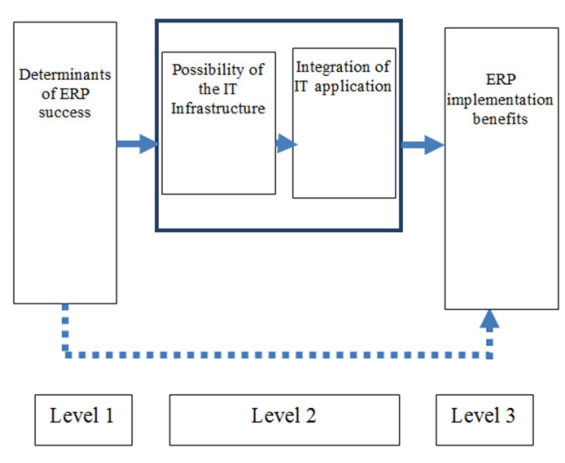

Fig. 2. The structure of the conceptual model

The questions asked are of two distinct types. Two open (non-directive) questions aiming to obtain information as freely as possible on the most important critical success factors and the benefits of ERP implementation. Through these two open questions, the objective was to find " indications as to the level of information of the person interviewed about what is central in his mind" [31]. Underlying questions of open (semidirective) types, aimed at obtaining information on categories of benefits and critical success factors, were developed on the basis of items and constructs identified from [18]. The analysis would then review all the trends from the different underlying issues and confront them later, with the constructs cleared of the main issues in order to infer the most significant variables to remember. For these variables to be definitively retained, it suffices that they are mentioned by more than $50 \%$ of the respondents at the level of the main question and also appear in an advanced position in the ranking made on the basis of this question.

Since the design of the research is a multi-site design, the analysis process consists, initially, in a separate study of each case separately and, in a second step, in an inter-site analysis [32]. The research field is made up of two parts involved in ERP projects, namely five ERP system suppliers and five industrial companies having had to implement at least four to six modules of an ERP software within the last two years. The 
interviewed specialists have experience in consulting several tenders, participating in many ERP projects, and have sufficiently experienced the effects on the organization of these IT. Thus, the main interlocutors, constituting the "theoretical sample" of the analysis, are project managers and general management executives who are deep involved in the implementation of the system and the monitoring of its operation. The expertise of the interviewees helps, in the sociocultural context of KSA companies, to give a specific representation of knowledge concerning the adoption of ERP systems and their success. This representation is confronted with a permanent comparison of the manipulated concepts and research variables.

\section{RESULTS AND INTERPRETATIONS}

\section{A. Benefits of Implementing an ERP System}

\section{1) Control of Information}

The content analysis of the interviews showed that respondents are unanimous on the control of information as a benefit provided by the ERP system. By acquiring an ERP solution, business managers seek, in fact, to solve problems related to the fluidity, availability and credibility of information. They are trying to limit the number of speakers and remove the dependency of people to access the information. They want the removal of personal links in the company and obtain full information transparency.

\section{2) Operational and Management Benefits}

Analysis shows improved performance control, cost control, time reduction, improved decision making, improved resource management, improved production management, and productivity as benefits provided by the establishment of an ERP system.

\section{a) Improved Performance Control}

According to interviewees, the system significantly improved performance control. It ensures "fairly rigorous activity control based on reliable and instantaneous information, generated in the form of report and dashboard". The analytic and multidimensional processing capability of the information also allows "a control of the performance by line of business, by product, by customer, by region or by different combinations". Using these reporting and analysis tools, the system improves the anticipation of problems relating, for example, to stock outage, quality deterioration and the overflow of cash facilities granted to customer and/or obtained from suppliers. With the automatic control procedures incorporated in the processes, the system also offers the possibility of "automatic blocking, if a critical threshold is exceeded" and encourages the employees of the company to "carry out their work on time so as not to block the process or be blamed by their colleagues".

\section{b) Cost Containment}

According to interviewees, the system has significantly improved cost control. With better information management and control, the system has generated "a certain ease and reliability in the calculation of technical costs, supply costs, commercial costs, and tooling costs". In this respect, one respondent stated that real-time cost control has led to, among other things, better monitoring of the waste rate and a waste reduction.

\section{c) Improved Decision-Making}

The system improved decision-making in the companies that have implemented it. For them, the control of information, brought by the new system, is at the origin of the improvement of the decision-making.

\section{d) Time Reduction}

The ERP system has also improved time efficiency in the companies that have implemented it. One respondent, pointed out that through some system-calculated indicators, such as the out-of-stock index, his firm was able to achieve a reduction in supply and delivery.

\section{e) Better Resource Management}

The ERP system allowed better management of fixed assets, receivables, stocks, etc. For some of the respondents, this improvement depends, in fact, on the degree of use of system functions. One respondent reported that "the system has been able to improve inventory management by minimizing dead stocks, which are usually caused by poor management at the supply and production levels".

\section{f) Better Production Management}

According to the interviewees, the system has generated a "better management of production" by optimizing production capacity. The management of computer-assisted production "GPAO" has led to an improvement in the planning and control of cost prices. This advantage is summarized in: "the production becomes a showcase, we can observe everything we want".

\section{g) Improved Productivity}

The interviewed suppliers suggested that there may be a few firms that have achieved an improvement in the level of productivity. They found, in this sense, better quality of the work done by the users of the system. They found "a decrease in the number of errors and an increased speed in carrying out the work". For some of them, it is the system in general and the self-checking procedures embedded in the processes, which have forced employees to be up-to-date in their work and which have "reduced seizure operations and forgetfulness".

\section{3) Strategic Benefits}

Improving customer satisfaction and tracking customers and suppliers are the reported strategic benefits of ERP systems.

\section{a) Better Customer Satisfaction}

According to the interviewees, the system has improved the satisfaction of customers. Respondents found better client management. For them the system has allowed a better response to customer needs. They note that the system has brought "a reduction in customer response times, a respect of delivery times, better management of rebates, discounts, customer returns and a better study of prices". The software also contributed to better customer order tracking. For the respondents, the improvement in customer satisfaction is 
essentially due to the different functionalities offered by the system and to the control of the information obtained as a result of its installation. Indeed, it is the accessibility of reliable information in real time, which allowed "a better customer follow-up".

\section{b) E-Business}

According to the interviewees, not all companies in Saudi Arabia use the possibilities of the ERP system to improve or establish possible electronic links between the company and its partners. If they have a website, its use is intended, generally, to present the company and its products. In this sense, respondents say that the majority of businesses have a website but virtually no link between the ERP system and their websites. However, a link is considered necessary for real-time management of customer and supplier relationships.

\section{c) Better Tracking of Customers and Suppliers}

The system has made it possible to better "identify sales and purchasing trends, anticipate customer needs and make decisions regarding procurement, delivery and customer or supplier settlement". For the interviewees, it is the information provided by the system that has made it possible to have better follow-up of the customers and better monitoring of suppliers (thanks in particular to a module dedicated to the management and monitoring of supplier performance). The system also provides alerts for both customers and suppliers and supports "better negotiation with customers and suppliers.

\section{4) Organizational Benefits}

Improving the use of skills, employee empowerment, communication and the development of a common language, are some of the benefits of ERP systems.

\section{a) Better Use of Skills}

According to respondents, the implementation of an ERP system can benefit employees by enabling them to acquire certain management and organizational skills. Interviewed companies report that the system has allowed users to improve their "control of tasks, behavior and organization in the work". The ERP system forced employees to be organized by imposing a very specific working method. The system allowed employees to have a better understanding of the interaction of management processes, to "practice management at the international level", to "get away from routine tasks, to focus on the aspects trades, and move on to analytical tasks". The system also promoted better use of certain management tools and techniques, such as dashboards, simulation techniques etc. and allowed employees to focus on their tasks. Employees will rid of the seizure routine and will move more toward control and analysis operations. In this case, the system has been able to improve the use of the talents and experiences of the employees. This new orientation has, to summarize, "the emergence of hidden skills which some employees had the opportunity to show".

\section{b) Empowerment}

The implementation of an ERP system can lead to greater autonomy for employees. The process editor module of the MFG/PRO solution, for example, provides each user with the ability to view his schematic workflow on his screen. The user's range of action is thus clearly defined: with a simple click, he can consult and visualize the different tasks to be performed. Users are also more autonomous regarding information: "They find all the information they need at their workstation".

\section{c) Improved Communication}

Respondents say that implementing an ERP system can improve communication throughout the company. For them, the system has allowed a certain speed of communication: "the communication is automatic, the system creates a purchase requisition, sends the request for approval to the hierarchical superior, before it is transmitted, then to the general direction for downstream and the service supply for ordering". This increased improvement in communication and information consolidation is largely due to the interoperability between applications. According to stakeholders, it seems that integration is the source of this improvement in communication.

\section{d) The Development of a Common Language}

The implementation of an ERP system standardized nomenclatures and documents. For the interviewees, an integrated system is synonymous with "the same for everyone", "same order form, same good of exit, same invoice". The employees speak the same language and share the same notions. Respondents consider that the system has allowed the development of a common language, notably through the standardization of work methods, tasks, and business processes.

\section{5) Conclusion}

The exploratory analysis of the ERP earnings data collected confirmed several operational, managerial, organizational and strategic benefits (Table II). However, the analysis of the interviews resulting from the control question brought out the control of information and the improvement of the use of skills as the two most important advantages provided by the ERP system. These two benefits are mentioned by more than $50 \%$ of the respondents. They thus occupy the top two positions in the overall ranking of ERP benefits, which are considered central by the respondents. Several studies have highlighted the relationship between IT adoption and organizational learning [18]. This work has shown that IT and application knowledge applications are key factors that facilitate organizational learning. Authors in [18] have shown that IT supports employee communication, facilitates the flattening of the organizational structure and the empowerment of employees. Exploratory analysis has brought out some aspects of this organizational learning. The analysis showed that the implementation of the system and its use can benefit employees by improving the use of certain skills. The concept: "better use of skills" is measured by two variables identified from the exploratory study: "mastering the work to be done" and the "use of certain tools and management techniques". Organizations typically adopt IT to improve the quality of information generated by their existing system and to strengthen their control over internal operations [33]. The need for better information can be considered, thus, as being at the origin of the need for integration of data and systems [33]. 
Exploratory analysis revealed four indicators or measurement variables of the "information control" concept, namely: availability, security, reliability and access to information.

TABLE II. ERP BENEFITS

\begin{tabular}{|c|}
\hline Control of information \\
\hline Improving the use of skills \\
\hline Cost control \\
\hline The reduction of deadlines \\
\hline Improved performance control \\
\hline Improving the management of resources \\
\hline Improvement of production \\
\hline Improving productivity \\
\hline Improving decision-making \\
\hline Improving the use of skills \\
\hline Empowerment \\
\hline Improved communication \\
\hline The development of a common language \\
\hline Improving customer satisfaction \\
\hline Improved tracking of customers and suppliers \\
\hline
\end{tabular}

\section{B. Determinants of Success}

The project team is an important factor in the successful implementation of an ERP system.

\section{1) The Quality of the Project Team}

Analysis of the collected data makes it possible to recognize that the implementation team is composed in most cases of company executives, informant and manager $(80 \%$ of respondents), ERP provider staff $(80 \%)$, consultant $(70 \%)$, super user "key users" (50\%), who have some control of the work processes of the company and rarely of newly recruited staff on the occasion of the project $(30 \%)$. The composition of the team shows that there is a combination of both technical and business aspects, both necessary for this type of project. The choice of a balanced team is emphasized by the respondents to meet the technical and business requirements of the project. This project team is generally composed, as almost all respondents indicate, of members with at least a few years' experience and good professional qualification. The majority of the team members have a university education. Professional experience and qualifications are important attributes of project team members. Most $(80 \%)$ of the respondents pointed out that in the majority of cases, team members cannot be assigned to the project on a full-time basis. The time that can be spent by the company's staff assigned to the project team can reach $50 \%$ to $70 \%$ of their overall time as the assigned staff has responsibilities and obligations regarding day-to-day operations. The full-time assignment of project team members is a feature of the project team. The training of team members is highlighted as an important feature. Respondents in all categories are unanimous on this point. Training sessions are organized for the benefit of the members of the project team by the supplier's staff. Finally, the respondents unanimously underline the importance of the presence of a project manager during ERP implementation. For them, the implementation team usually has a project manager with technical and business skills. For the purposes of the project, IT knowledge and knowledge of procedures, user and management expectations, and company management rules are necessary for the smooth running of the project. The project leader is qualified by the respondents as a leader without being authoritarian, with charismatic personality, good interlocutor, communicator, conflict manager, good decision-maker and someone who has a sense of consensus. The presence of a project manager in the team is a feature of great importance to the project team. A quality project team is, in short, a well-rounded, experienced team of qualified people who have been trained and who have a skillful project manager.

\section{2) The Mission of the Project Team}

Interviewees unanimously stressed the importance of defining the mission of the project team. An interviewee pointed out that "the supplier usually has a management plan for setting up an ERP system. This plan specifies the role of each stakeholder in the mission". The definition of the mission is integrated at the contract level, in order to set the responsibilities and the right of each party. The mission of the project team is sometimes fixed or documented at the level of the specifications or the contract.

\section{3) The Presence of a Champion or a Sponsor}

Respondents say there may be one or two people who can play a vital role in the project. These people have the role of reinforcing the commitment of staff to the project, anticipate conflicts, prevent financial overflows, facilitate the task of the ERP provider, etc. For the respondents, this "champion" has several qualities: he is a good communicator, diplomat, arbitrator, he has the power to easily influence decisions and to intervene, if necessary, with the general management. With the exception of a few cases where the sponsor may be a key user or a member of the project team, the champion usually belongs to the senior management of the organization. The respondents consider a position at the higher hierarchical level as a necessary condition, so that the sponsor plays its full role. In this regard, the sponsor may be the head of the company, a senior executive close to the director, an IS director, a management controller, a project manager, etc.

\section{4) Users of the ERP System}

The analysis shows that training, user acceptance and user satisfaction are success factors for ERP projects. No interviewee mentioned user participation as a key success factor. According to the respondents, the users do not have an essential role in the implantation, and they "have a role only after implantation in optimization or improvement of the use of the system". Their contributions are limited to providing the project team with the information needed for the "needs analysis and parameterization" tasks. In addition, the analysis showed unanimity of interviews on the importance of training users in this type of project. According to respondents, the participation of users in training sessions is necessary for the efficient operation of the software package. This training is generally provided by the staff of the company and more specifically by the project team and/or rarely by the staff of the integrator or the supplier, often performed on all functionalities and modules. Moreover, the analysis showed that the users do not easily accept the ERP system at the beginning of the project. Only one vendor mentioned that user acceptance of the system is necessary for ERP success. According to the respondents, "the users think only of their interests, they are not 
convinced of the interest of the ERP, since the old system is easier to use". Interviewees find that the difficulties and complexities of the system features make users afraid to use it. One respondent stated, that "users do not easily accept the ERP system because of the phobia of the new". However, the intervention of the general management makes that users begin to accept the system after some time: "users are starting to apologize and defend the system, almost after a few months". In a similar way, the analysis initially revealed unanimity on the satisfaction of the users as being an important factor for the success of the ERP implementation. According to the interviewees, the users are generally satisfied after some time of experimentation with the system and its effective exploitation: "users are only satisfied with the system after six months of operation". This can be explained by their resistance manifested at the beginning of the project, and by the fact that the information provided by the system does not fully meet their needs. For the interviewees the satisfaction of the users comes, generally, in the ex-post phase of the ERP implementation. Nonetheless, respondents say that user satisfaction is not complete, since they continue to use manual entry techniques, prepare reports using excel spreadsheets, and maintain old ones.

\section{5) Communication}

Analysis showed that users are not kept informed of the progress of the project in a formal way. Communication is not considered a key factor in the success of ERP projects. According to the respondents, the users "often bathe in vagueness and confusion". If they are informed about the progress of the project, it is by means of some information flashes and informally. People who are most knowledgeable about the progress of the project often belong to the project team, the general management and the great users. For these stakeholders, regular kick-off meetings are the main source of information. The resulting decisions are formalized in the form of "signed minutes, internal notes, posters, e-mails", often conveyed informally.

\section{6) Project Management}

The exploitation of the collected data makes it possible to recognize that the rigorous management of the project is an important factor in the successful implementation of the ERP systems. The definition of objectives and the precision of the fields of application of the project are recognized by the respondents as a key factor of success. According to the respondents, the objectives are defined in the initiation phase of the project. They appear formally "on the specifications or at the level of the call for tenders launched by the company". The analysis recognizes that preparing a project plan/schedule is a key success factor. The project plan and schedule are designed, generally, in a systematic way. Integrator and client collaborate for the overall project planning. Together, they design a precise project implementation schedule and specify the objectives of each stage of the project.

Setting up an ERP system requires the use of a project methodology. All interviewees are unanimous on this point. According to them, when the company does not develop a methodology by itself, the providers have and apply their own implementation approach and project management methodology. In coordination with the rest of the project team, integrators (rarely companies) sometimes use project management tools such as MS Project. Some ERP solutions even have integrated project management tools, in this case the "Oracle Wizard" of the Oracle solution. A project with small fields and restricted functionalities is more likely to succeed. None of the interviewed companies mentioned this element of response, whereas nearly $60 \%$ of the providers consider that this element is a key factor of potential success. According to respondents, businesses are "afraid to upset all their areas of activity". They are much more supportive of a step-by-step strategy for implementing the ERP system. In summary, rigorous management is a project management which involves the definition of the objectives, the precision of the field, the fixing of a plan, a calendar and the application of a project methodology.

\section{7) Control}

Analysis showed that problem-solving (supervision and feedback) is one of the critical factors in successful ERP implementation. According to the respondents, many problems can arise during the project: problems of resistance and noninvolvement of a part of the staff, high rotation rates, resignations of key people, unavailability of customer personnel, deadline non-compliances, absence of a procedures manual, slowness of the validation of decisions, etc. These problems are overcome by the "relational" and the intervention of the project manager and/or the general management. For the respondents, the difficulty of defining the needs during the preparation of the specifications and/or during the evaluation test that precedes the acquisition of the system (the providers execute the specifications provided by the company) is at the root of these problems. Companies generally exercise tight control over the project's achievements. This interest is justified by: "companies pay for the acquisition and implementation of this system", and "would like and expect results". Several ways are used for the supervision of the progress of the project, such as: reception PV, project dashboards, activity reports, echoes or feedback from users, etc. Supervision is carried out by the project team, the project management team (firm and external consultant) and/or the general management. It is on the basis of the periodic accounts that the project manager and the management will intervene to find suitable solutions.

\section{8) Top Management}

Analysis showed the importance of the role of senior management in the success of ERP projects. Important, primordial, strategic, philosophical, stimulating, motivational are terms that often came up by the respondents to describe the role of the general management in the process of implementing an ERP system. For the respondents, the management mobilizes the necessary resources (human, material, financial) and ensures the permanent monitoring of the progress of the project. It also intervenes in case of resistance to change or in case of conflict and/or blockage.

\section{9) Business Process Reengineering}

Data mining recognizes that business process reengineering can be seen as a success factor for ERP projects. It plays a 
decisive role in obtaining the benefits projected by companies that have adopted an ERP system. The analysis showed that the implementation of an ERP is usually preceded by identification and modeling of the main business processes of the organization: "the diagnosis often requires the visualization of existing processes". This visualization supports the implementation of the ERP, by identifying the processes to keep, to reject and those to improve in order to increase the performance of the case. These processes can sometimes be modeled using software tools or a modeling tool incorporated into the ERP system. The parties involved in this operation may be the project team (client and integrator), the process managers, the key users, or the consultant firms. Analysis showed almost unanimity regarding the review of pre-planted business processes. According to the respondents, this reconfiguration aims to respond to the solution desired by the customer and improve the performance of business processes. Generally, the "unorganized, unclear and problematic processes" would be reviewed. This operation is usually performed in parallel with the installation of the system, by calling on the services of the integrator or consultants. The analysis also revealed the revision of the content of the functions as a serious element in the success of the implementation of an ERP. According to the respondents, the implementation is "an opportunity to review the content of the functions of the employees of the company". It is considered as a consequence of implementation, which requires the deletion, modification and/or addition of certain tasks.

\section{0) Selection of the ERP Solution}

The data collected makes it possible to recognize that the selection of an ERP solution (the selection of the appropriate software package and the supplier/company relationship) is considered as a key success factor for ERP projects. According to the respondents, evaluating ERP solutions on the market is a key step in the process of adopting ERP innovation. The purpose of this step is to choose the software package that best suits the business processes of the company. In fact, ERP solutions differ from one business sector to another and the solution that best fits the needs defined by each company should be chosen. For the purposes of this step, the companies proceed, initially, to the elaboration of specifications based on the analysis of the needs and the offers on the ERP software market. "This step can take up to one year and a half". The evaluation of the selected software packages (preliminary study) is carried out according to several criteria, such as the competence of the ERP supplier team and the availability of human resources necessary for the smooth running of the project. Finally, the selected software packages are the subject of a demonstration and a real test before the final decision of its acquisition. The purpose of this demonstration is to show mainly whether the ERP model can correspond to the management model of the company or not. The careful choice of the appropriate software package can be retained as a useful element for the successful implementation of an ERP system. Another critical element is the supplier/company relationship. According to the respondents, the presence of a serious and confident relationship between the buyer and the ERP supplier is important. Companies require the ERP provider, in particular, the human resources necessary for the smooth running of the project. They insist on the "competence and availability of the integrating team". Generally, KSA companies use the service of their ERP suppliers to help them set up the acquired system. In this case, they are called upon to seek not only the software package that best suits their needs, but also to ensure also the choices of the supplier with the human resources necessary for the proper project completion. The interviewed companies realized, indeed, that quality of the service, know-how, experience and availability of the integrator's team, are necessary for the success of the project.

\section{1) Conclusion}

The exploratory analysis thus confirmed the results of other theoretical studies, highlighting the presence of several success factors relating to ERP projects (Table III). The factors in Table III are mentioned by at least $50 \%$ of the respondents. They are in the top five ranks in the overall CSF ranking, and considered essential by the respondents. The exploratory analysis also highlighted several features of the ERP implementation team. All of these distinctive are grouped into two measurement variables distinct from the concept "quality of the project team", "composition of the project team" and "project team capacity".

TABLE III. KEY FACTORS OF SUCCESS

\begin{tabular}{|c|}
\hline The quality of the project team \\
\hline The mission of the project team \\
\hline The presence of a champion or a sponsor \\
\hline User training \\
\hline User acceptance \\
\hline Rigorous management of the project \\
\hline Control \\
\hline The commitment of the general management \\
\hline Business process reengineering \\
\hline The ERP/business provider relationship \\
\hline
\end{tabular}

\section{CONCLUSIONS}

This research study aims to provide elements for understanding the success of implementing ERP systems in an emerging country context where SMEs constitute the bulk of the economic fabric. To answer this problem, a theoretical research framework was developed by exploiting theories and models that deal with the success of information systems. Two main theories have been mobilized: strategic alignment [34] and diffusion of innovation [13]. Various models inherent to IT adoption and evaluation were also used $[25,35]$ to define the theoretical model of this research. This model aims to examine the effect of the relationship between the determinants of success and the characteristics of innovation as well as the integration of IT applications on the success of ERP adoption, applied to KSA companies, by analyzing the experience of five ERP suppliers and five companies having installed such systems. The experience feedback presented in this work helped to consolidate the conceptual model adopted after the theoretical analysis (Figure 2). The results of the exploratory study made it possible to specify, relativize and even eliminate a number of elements that were tested in KSA and tended to be considered as central or fundamental. 


\section{REFERENCES}

[1] B. Caldwell, Stein, "Beyond ERP -- New IT Agenda -- A Second Wave of ERP Activity Promises to Increase Efficiency and Transform Ways of Doing Business", InformationWeek, No. 711, 1998

[2] L. Singletary, Empirical Study of Attributes and Perceived Benefits of Applications Integration for Enterprise Systems, PhD Thesis, Louisiana State University, USA, 2003

[3] C. Stedman, "ERP User Interfaces Drive Workers Nuts", ComputerWorld, Vol. 2, pp. 1-24, 1998

[4] B. Gowigati, B. Grenier, "The Winds of Change", CMA Management, Vol. 75, No. 8, p. 34, 2001

[5] S. Mekadmi, S. Baile, "Impact de la culture organisationnelle dans une demarche d'implantation des systemes d'entreprise", 11eme Colloque international de l'AIM, Universite du Luxembourg, June 22, 2006 (in French)

[6] E. L. Appleton, "How to survive ERP”, Datamation-Highlands Ranch, Vol. 43, No. 3, pp. 50-55, 1997

[7] K. C. Laudon, J. P. Laudon, Organization and Technology in the Networked Enterprise, Prentice-Hall, 2001

[8] G. Stewart, M. Milford, T. Jewels, T. Hunter, B. Hunter, "Organisational Readiness for ERP Implementation”, in: AMCIS 2000 Proceedings, pp. 966-971, AIS Electronic Library, 2000

[9] A. N. Parr, G. Shanks, P. Darke, "The Identification of Necessary Factors For Successful Implementation of ERP Systems", in: New Information Technologies in Organisational Process, Kluwer Academic Publishers, pp. 99-119, 1999

[10] C. R. Holland, B. Light, "A Critical Success Factors Model for Enterprise Resource Planning Implementation”, IEEE Software, Vol. 16, No. 3, pp. 30-36, 1999

[11] W. H. De Lone, E. R. McLean, "The Quest for the Dependent Variable", Information Systems Research, Vol. 3, No. 1, pp. 60-95, 1992

[12] K. C. Laudon, J. P. Laudon, Management Information Systems: Managing the Digital Firm, Pearson Education USA, 2018

[13] E. M. Rogers, Diffusion of Innovations, Free Press, 2003

[14] R. I. Benjamin, E. Levinson, “A framework for managing IT-enabled change”, Sloan Management Review, Vol. 34, No. 4, pp. 23-33, 1993

[15] W. Bussen, M. Myers, "Executive Information Systems Failure: a New Zealand Case Study", Journal of Information Technology, Vol. 12, No. 2, pp. 145-153, 1996

[16] M. Saleh, M. Abbad, M. Al-Shehri, "ERP Implementation Success Factors in Saudi Arabia”, International Journal of Computer Science and Security, Vol. 7, No. 1, pp. 15-30, 2013

[17] A. Al Qashami, H. Mohammad, "Critical Success Factors (CSFs) Of Enterprise Resource Planning (ERP) System Implementation in Higher Education Institutions (HEIs): Concepts and Literature Review", ICAITA, Dubai, UAE, 2015

[18] S. Shang, P. B. Seddon, "A Comprehensive Framework For Classifying the Benefits of ERP Systems", 2000 Americas Conference on IS, Long Beach California, USA, August 10, 2000

[19] M. L. Markus, C. Tanis, "The Enterprise Systems Experience- From Adoption to Success", in: Framing the Domains of IT Research: Glimpsing the Future Through the Past, Claremont Graduate University, California, pp. 173-206, 1999

[20] M. A. Hitt, E. Hoskisson, R. D. Nixon, “A Mid-range Theory of Interfunctional Integration, its Antecedents and Outcomes", Journal of Engineering and Technology Management, Vol. 10, No. 1, pp. 161-185, 1993

[21] J. W. Beard, M. Sumner, "Seeking strategic advantage in the post-net era: viewing ERP systems from the resource-based perspective", Journal of Strategic Information Systems, Vol. 13, No. 2, pp. 129-150, 2004

[22] D. M. Fisher, M. Y. Kiang, S. A. Fisher, R. T. Chi, "Evaluating midlevel ERP software", Journal of Computer Information Systems, Vol. 45, No. 1, pp. 38-46, 2004

[23] T. H. Davenport, Mission Critical-Realizing the Promise of Enterprise Systems, Harvard Business School Press, Boston, Massachusetts, 2000
[24] K. Crowston, M. E. Tracey, "Assessing the impact of information technology on enterprise level performance", Sixth International Conference on Information Systems (ICIS), Indianapolis, USA, 1986

[25] H. Barki, A. Pinsonneault, "The Construct of Organizational Integration: A Research Framework and Its Application to Enterprise Systems Research", Cahier du GReSI, No. 03-04, 2003

[26] V. Kumar, M. Bharat, U. Kumar, "An investigation of critical management issues in ERP implementation: empirical evidence from Canadian organizations", Technovation, Vol. 23, pp. 793-807, 2003

[27] H. Barki, A. Pinsonneault, "A model of organizational integration, implementation effort, and performance". Organization Science, Vol. 16, No. 2, pp. 165-179, 2005

[28] V. A. Mabert, A. Soni, M. A. Venkataramanan, "The impact of Organization Size on Enterprise Resource Planning (ERP) Implementations in the US Manufacturing Sector", Omega, Vol. 31, No. 3, pp. 235-248, 2003

[29] B. G. Glaser, A. L. Strauss, The Discovery of Grounded Theory: Strategies for Qualitative Research, De Gruyter, 1967

[30] R. Suddaby, "From the Editors: What Grounded Theory is not", Academy of Management Journal, Vol. 49, No. 4, pp. 633-642, 2006

[31] J. Powney, M. Watts, Interviewing in Educational Research, Routledge, 1987

[32] R. K. Yin, "Discovering the Future of the Case Study Method in Evaluation Research", Evaluation Practice, Vol. 15, No. 3, pp. 283-290, 1994

[33] D. Oliver C. Romm, “Justifying Enterprise Resource Planning Adoption", Journal of Information Technology, Vol. 17, No. 4, pp. 199213, 2002

[34] J. Henderson, N. Venkatraman, "Strategic Alignment: Leveraging information technology for transforming organizations", IBM Systems Journal, Vol. 32, pp. 4-16, 1993

[35] E. Erturk, J. K. Arora, “An Exploratory Study on the Implementation and Adoption of ERP Solutions for Businesses", available at: https://arxiv.org/ftp/arxiv/papers/1701/1701.08329.pdf, 2017

[36] U. Jayawickrama, "Knowledge prioritisation for ERP implementation success: perspectives of clients and implementation partners in UK industries", Industrial Management \& Data Systems, Vol. 117, No. 7, pp. $1521-1546,2017$ 